\title{
Risk Grubu Öğrenciler İçin Gönderme Öncesi Süreçte Veriye Dayalı Karar Verme
}

\section{Data-Driven Decision Making in the Pre-Referral Process for Risk Group Students}

\section{Nilüfer Altun, Necdet Karasu}

\section{Yazar Bilgileri}

Nilüfer Altun

Arş. Gör., Gazi Üniversitesi,

Gazi Eğitim Fakültesi, Özel

Eğitim,

naltun@gazi.edu.tr

\section{Necdet Karasu}

Prof. Dr., Gazi Üniversitesi, Gazi Eğitim Fakültesi, Özel Eğitim,

necdetkarasu@gazi.edu.tr

\section{ÖZ}

Bu çalışma, sınıf öğretmenleri tarafından akademik ya da davranışsal olarak risk grubu olduğu düşünülen öğrencilerin özel eğitim hizmetlerine uygunluğu için yönlendirilmesinden önceki süreçte veriye dayalı karar vermenin kullanılmasına ilişkin durumu ortaya koymayı amaçlamaktadır. Çalışmada, sınıf içi izleme ve değerlendirme süreçleri, gönderme öncesi süreç ve bu sürecin öğrencilerin eğitim hayatı açısından önemi, veriye dayalı karar verme ve gönderme öncesi süreçte veriye dayalı karar vermenin önemi açıklanmaya çalışılmıştır. Bir öğrencinin öğrenme özellikleri hakkında bilgi sahibi olunması sınıf içi izleme ve değerlendirme ile öğrenciye ilişkin ne zaman, ne kadar ve nasıl veri toplandığına bağlıdır. Sınıf içerisinde her bir öğrenci kendi öğrenme özellikleri ile ilerlemektedir ve bu özellikler öğrencilerin destek ihtiyacının da göstergesidir. Öğretmenlerin her bir öğrencisinin öğrenme özelliğine uygun düzenlemeleri yapabilmesi için veri toplamaları, verileri sınıflamaları ve kararların eyleme dönüştürdükleri veriye dayalı karar verme sürecini etkin kullanmaları önemlidir. Risk grubu olarak düşünülen öğrencilere yönelik ise veriye dayalı kararların alınması öğrencilerin bulundukları eğitim ortamından yararlanmalarını önemli ölçüde etkilemektedir.

\section{Makale Bilgileri \\ Anahtar Kelimeler Gönderme Öncesi Süreç Veriye Dayalı Karar Verme Risk Grubu Öğrenciler Sınıf İçi İzleme ve Değerlendirme \\ Keywords \\ Pre-Referral Process \\ Data Driven Decision Making \\ Risk Group Students \\ In-Class Monitoring and \\ Evaluation}

\section{Makale Geçmişi}

Geliş: 30.03.2021

Düzeltme: 25.04.2021

Kabul: 01.05.2021

\begin{abstract}
This study aims to reveal the situation regarding the use of data driven decision making in the process before students' being guided by classroom teachers to be an academically or behaviorally at risk group for special education services. In the study, in-class monitoring and evaluation processes, the pre-referral process and the importance of this process in terms of students' educational life, the importance of data-driven decision making and data-driven decision making in the pre-referral process were tried to be explained. Learning about a student's learning characteristics depends on when, how much and how data is collected through in-class monitoring and evaluation. In the classroom, each student progresses with his or her own learning characteristics. These features are also indicators of students' need for support. It is important for teachers to collect data, classify data and use the data-driven decision making process, in which they turn their decisions into action, so that they can make appropriate adjustments to the learning characteristics of each student. For students who are considered as a risk group, making decisions driven on data significantly affects students' ability to benefit from the educational environment they are in.
\end{abstract}




\section{Giriş}

Kararlar öğrencilerin eğitim hayatı içerisinde önemli yer tutmaktadır. Öğretmenler öğrencileri söz konusu olduğunda onlar için fark etmeseler de sürekli ve çeşitli kararlar almaktadır. Öğretmenler öğrencilerini tanıma sürecinden başlayarak, onların akademik hayatlarını doğru yönlendirmek için bir takım değerlendirmeler sonucu elde ettikleri verilerden oluşturdukları bilgi bütününün oluşturduğu anlama dayanarak karar vermelidirler. Öğrencinin akademik hayatına yön vermek sınıf içi izleme ve değerlendirmelerin etkin bir şekilde yapılması ve sonuçlarının kullanılması süreci ile başlamaktadır. Öğretmen sınıf içi izleme ve değerlendirmeler sonucunda öğrencilerini her anlamda elindeki verilere dayalı olarak tanımaya başlamaktadır. Sürecin devamında öğrencilerinin farklı öğrenme özelliklerini belirler ve bunun farkında olur. Farklı öğrenen öğrencileri için verebileceği destek için de sınıf içi izleme ve değerlendirme yapmaya ve karar vermeye devam etmektedir. Sınıfında akranlarından giderek farklılaştığını gördüğü öğrencileri için eğitim-öğretim süreçlerinde düzenlemelere giderek yararı üzerinde sınıf içi izleme ve değerlendirmelerine devam eder ve öğrencisini her bir basamakta daha iyi tanımak için elde ettiği verilere dayalı olarak süreci yönetir. Verilere dayalı yönettiği bu süreçte öğretmenin elinde öğrencisi hakkında anlamlı bir bilgi bütünü oluşmuş olur ve bu bilgi doğrultusunda daha nitelikli, işlevsel ve doğru kararlar vermiş olur. Bu çalışmada öğrenciyi tanımak için yapılan sınıf içi izleme ve değerlendirmeden başlayarak, risk grubu öğrenciler, bu öğrenciler için eğitsel anlamda işleyen gönderme öncesi ve eğitsel tanılama ve değerlendirme sürecini veriye dayalı karar verme temelinde açıklamakla birlikte veriye dayalı karar vermenin gönderme öncesi süreçteki önemine yer vermektedir.

\section{Sınıf İçi İzleme ve Değerlendirmenin Öğrenmenin Planlanması Üzerine Etkisi}

Değerlendirme, sınıf ortamının olmazsa olmaz ve sürekliliği olan bir parçası olarak karşımıza çıkmaktadır (Russell ve Airasian, 2012). Öğrencide öğrenmenin gerçekleştiği ya da gerçekleşmediği ancak değerlendirme sonuçlarıyla ortaya konulabilir. Sınıf içi izleme ve değerlendirme, öğrencilerin kazanımlarını izleme ve öğrencilerin eğitim-öğretim sürecini şekillendirmeye yönelik karar vermek için veri elde etme süreci olarak belirtilmektedir (Overton, 2012; Russell ve Airasian, 2012; Salvia, Ysseldyke ve Bolt, 2010; Tomlinson ve Moon, 2013). Sınıf içi izleme ve değerlendirme öğrencilerin ilerlemelerini belirlenmiş olan müfredat hedefleri ile karşılaştırmak üzere bilgi edinme süreci olarak tanımlanmaktadır (Shermis ve DiVesta, 2011). Bu bilgi edinme sürecinde elde edilen veri öğrenci ile ilgili bir anlama bürünerek öğretmenlerin sınıf içinde düzenleme ve planlamaları için temel karar verme kaynağı haline dönüşürler.

Sınıf içi izleme ve değerlendirme süreci, bir sınıf içinde bilgiyi toplamayı, yorumlamayı ve kullanmayı içermektedir. Öğretmenler, sınıfta değerlendirmenin birincil sorumlularıdır ve değerlendirmeler sonucu oluşan bilgileri öğrencilerinin öğrenmelerini desteklemek için kullanırlar 
(Chen ve Bonner, 2020; Kane ve Wools, 2020). Sınıf içi izleme ve değerlendirme yapmanın amaçları arasında öğrenciler arasındaki bireysel farklılıkları belirlemek, öğretimi planlamak ve yürütmek, öğrencilere geri bildirim ve motivasyon sağlamak, öğrencilerin risk durumlarını ve destek eğitime ihtiyaç durumunu belirlemek ve ilerlemeleri değerlendirmek yer almaktadır (Frey, 2019; Russell ve Airasian, 2012). Yapılan değerlendirmeler sonucu oluşan bilgi, öğretmenler için bir geri bildirim niteliğindedir. Sınıf içi izleme ve değerlendirme ile elde edilen geri bildirim, öğretim yöntemlerinde değişiklik ihtiyacını belirleme, bireysel farklılıkları göz önünde bulundurma, öğrenci gelişimi açısından öğretimi izleme, öğrenci performansına uygun müfredat hedefi belirleme, etkili öğretim için öğrenci performansına uygun stratejileri belirlemeye yönelik kararların alınmasında öğretmene yardımcı olmaktadır (Shermis ve DiVesta, 2011).

Öğrenci hakkında bilgi edinmek için ilk adım değerlendirme yaparak veri toplamaktır. Bu nedenle öğretmenler farkında olarak ya da olmayarak öğrencilerini pek çok şekilde değerlendirirler (Anderson, 2003). Değerlendirme kavramı sıklıkla sınav yapmak ve not vermekle ilişkilendirilmektedir. Bu değerlendirme anlayışı, eğitim-öğretim sürecini yönetmek ve değerlendirme sonuçlarının eğitim faaliyetlerinin etkili kullanımı açısından öğretmeni sınırlandırmaktadır. Öğretmen bu bakış açısıyla değerlendirmenin öğrenciler bakımından öğrenme, kendi açısından öğretme sürecindeki önemini geri plana itmektedirler. Öğretmenlerin sürekli ve çeşitli yollardan öğrencilerini değerlendiriyor olmaları, öğrencilerin gereksinimleri olduğu anı belirleyebilmek için çok kıymetlidir. Sınıf içi izleme ve değerlendirme veri toplama gerekliliğini getirir, devamında verilerden elde edilen bilgi gereksinimler doğrultusunda öğretim sürecinde yapılması gereken değişikliklere yön vermektedir (Overton, 2012).

Öğretmen plan yapmak ve öğretim süreci şekillendirmek için belli kararlar vermelidir. Öğretmen eğer başarıyı belirlemek istiyorsa, veriyi mümkün olduğunca karara yakın toplamalıdır. Öğrenmeye ilişkin bilgi elde etmek istiyorsa süreç içinde veri toplamaya yönelik bir plan yapmalıdır (Anderson, 2003). Öğretim süreci içerisinde veri toplama zamanları öğretimden önce, öğretim sırasında ve öğretimden sonra olarak sıralanabilir (McMillan, 2017; Özmen, 2012; Shermis ve DiVesta, 2011; Tomlinson ve Moon, 2013). Öğretim öncesi öğrencilerin hazır bulunuşluklarını belirlemek, öğretime nereden başlayacağını planlamak, öğretimde gereksinim duyulabilecek farklı yöntem, teknik, ortam düzenlemesi ya da materyaller için hazırlık yapmak adına izleme ve değerlendirme yapılması önemlidir. İzleme ve değerlendirme benzer şekilde bir önceki öğrenmelerin de kalıcılı̆̆ının belirlenmesi amacına da hizmet etmektedir (Black, 1983; Shermis ve DiVesta, 2011). Öğretmenin ilerlemeleri kontrol etmesi ve sürece hâkim olmasını sağlamasına öğretim sırası izleme ve değerlendirme sonuçları yardımcı olmaktadır. Öğretim sırası izleme ve değerlendirme öğretmene, öğrenci performansından elde edilen bilgileri kullanarak, öğrencilerin öğrenmelerine anında 
müdahale etme imkânı sağlar. Öğretimin değiştirilmesi ya da geliştirilmesi gereken kısımlarını görme imkânı sunar. Öğretim sırası izleme e değerlendirme aynı zamanda öğrencilerin öğrenmelerinde farklılaşan noktaların da görünmesini, farklı öğrenen öğrencilerin belirlenmesini sağlar (Anderson, 2003; Saefurrohman ve Balinas, 2016; Shermis ve DiVesta, 2011). Öğretim sonrası değerlendirme, ders sonunda, öğretim sonunda öğrencinin ne derecede öğrendiğine ilişkin öğretmene veri sağlar. Bu veriler 1şığında öğretmen, süreçte yaptığı değişikliklerin etkililiğini ve öğrencinin edinim düzeyine ilişkin verileri yorumlayıp bilgi sahibi olur (Black, Wilson ve Yao, 2011; Shermis ve DiVesta, 2011). Öğrencilerin farklı öğrenme özelliklerinin belirlenmesi, sınıf içinde öğretimin, izleme ve değerlendirmenin farklılaşması gereken noktalarına odaklanması için öğretmene yol gösterecektir. Öğretmen, öğretim sürecini ve değerlendirme araçlarını zenginleştirecek ve tüm öğrencilerine hitap edecek şekilde düzenleyecektir. Değerlendirme sınıf içinde sürekliliği olan bir rol üstlenmektedir. Sürekli yapılan değerlendirmeler farklı ya da ek desteğe ihtiyaç duyan öğrenciler için öğretmenler önlem almak üzere bilgi sahibi olmalarını sağlamaktadır. Farklı ya da ek desteğe ihtiyaç duyan öğrencilerin sosyal-duygusal, davranışsal ve akademik özelliklerinin belirlenmesi, ihtiyaçlarına yönelik önlem alınması bu öğrencilerin öğretim süreçlerine yön verilmesi adına önemlidir.

\section{Risk Grubu Öğrenciler}

Bir sınıfta bireysel öğrenme özellikleri bakımından çok çeşitli öğrenci ya da öğrenci gruplarıyla karşılaşılmaktadır. Öğrenciler sosyal-duygusal davranışları, iletişim tercihleri veya öğrenme yolları bakımından çok farklı, kendine has özelliklere sahip olabilirler. Çeşitli özellikleri olan öğrencilerin olduğu bu sınıfın içerisinde öğretmenlerin belirli bir grup içine girmeyen öğrencileri için bir tanımlama yapması gerekebilir. Bu bağlamda risk grubu öğrenciler ifadesi, farklı bir öğrenci kategorisine atıfta bulunma ihtiyacı duyduğumuzda karşımıza çıkmaktadır (Sagor ve Cox, 2013). Okul ortamında öğrencinin performansını olumsuz etkileyen sosyal, akademik, duygusal, davranışsal, dil ya da sağlık açısından algısal veya çevresel kaygılar yaşayan bir öğrenci risk grubu öğrenci olarak belirlenmektedir (Pierangelo ve Giuliani, 2007). Çeşitli risk faktörleri temelinde okuldan mezun olma ihtimali düşük olan öğrenciler de risk grubu öğrenciler olarak tanımlanmaktadırlar. Diğer risk faktörleri arasında düşük başarı, sınıfta kalma, sosyal-uyumsal ya da davranış sorunları, düşük devam, düşük sosyo-ekonomik düzey ya da sosyo-ekonomik düzeyi düşük olan öğrencilerin bulunduğu okullara devam etmemesi sayılmaktadır (Flaherty ve Osher, 2003; Slavin ve Madden, 1989; Tunç, 2011; Weist, 1997). Risk grubu öğrenciler ile okulun başladığı yıllarda karşılaşabileceği gibi (Vaughn, Bos ve Schumm, 2018) okulun devam ettiği süreçlerde de karşılaşılabilir.

Öğretmenler risk grubu öğrencileri sınıf ortamında fark etme aşamasında birincil ve güvenilir kaynaktır (Gresham, 1997). Öğrencilerin bireysel farklılıkları olduğunu, farklılıkların olmasının 
normal olabileceğini vurgulayan öğretmenler, bu öğrencileri içinden fazla desteğe ihtiyaç duyan öğrencilerin belirlenmesinin önemli olduğunu belirtmişlerdir (Çuhadar, 2017). Öğretmenler, genel eğitim sınıflarında bulunan bazı öğrencilerin geleneksel öğretim yöntemleri ile öğrenemediğini (McAlenney ve Coyne, 2011), akranlarından giderek farklılaştığını belirtmişler ve çoğunlukla deneyimleri, gözlemleri ve değerlendirme sonuçları doğrultusunda buna karar verdiklerini ifade etmektedirler.

Sınıf içinde farklı gelişim gösterdiği fark edilen öğrenciler için öğretimin ve öğrenme ortamının farklılaşması gereken noktaları belirlemeye yönelik girişimlerin başlangıç noktası veri toplamaktan geçmektedir. Öğrenciler hakkında veri toplamaya yönelik yapılan sistematik olarak sınıf içi izleme ve değerlendirme, öğrencilere yapılacak olan uyarlamaların, düzenlemelerin hangi öğrenciye ne oranda yapılacağı konusunda öğretmene yol göstermektedir. Toplanan veri ve devamında elde edilen bilgiler doğrultusunda risk grubu öğrenci veriye dayalı olarak belirlenmiş ve bu doğrultuda eğitim sürecine devam ediyor olacaktır. Bu çalışma risk grubu öğrenciler, fark etme ve gönderme öncesi süreçte öğretmenin sınıf içi izleme ve değerlendirme adına yaptığı çalışmalar çerçevesinde ele alınmıştır. Öğretmenlerin gönderme öncesi sürecin ne anlama geldiğini bilmeleri, gönderme öncesi süreçte öğrencileri adına yapılacakların farkında olmaları gerek sınıf içinde öğrencilerine sağlayacakları desteğe karar verme, gerekse eğitsel tanılama ve değerlendirmeye yönlendirilmesi gereken öğrencilere yönelik karar verme sürecini yönetebilmelerini sağlayacaktır.

\section{Gönderme Öncesi Süreç ve Eğitsel Tanılama ve Değerlendirme}

Eğitsel değerlendirme ve tanılama, öğrencinin tıbbi tanısına ek olarak eğitsel performansının ve eğitim hayatına devam edeceği ortamın belirlenmesi, bu ortamda kullanılacak gerekli program, materyal ve destek eğitim uygulayıcıları ile ilgili kararı verilmesidir (Özyürek, 2015; Strickland ve Turnbull, 1990). Öğrenciye verilecek eğitsel tanı için yapılacak değerlendirmenin amacı, öğrencinin özel eğitim hizmetlerine ihtiyacını belirlemek ve ihtiyaç halinde bu hizmetlerin ne olacağını belirlemektir (Reschly, 1996). Ülkemizde Özel Eğitim Hizmetleri Yönetmeliğine (ÖEHY) göre eğitsel tanı özel eğitim ihtiyacının tespiti için yapılmaktadır. ÖEHY'ne göre eğitsel tanılama süreci, eğitsel değerlendirme ve tanılama, eğitim planı hazırlama, yönlendirme ve izleme aşamalarından oluşmaktadır (Milli Eğitim Bakanlığı [MEB], 2018b).

Risk grubu olduğu düşünülen bir öğrenci, alan yazında eğitsel değerlendirme ve tanılama olarak belirtilen ilk iki basamağı ilk belirleme/tarama, gönderme öncesi süreç ile başlayan eğer ihtiyacı olan destek eğitim hizmetini bulunduğu sınıf ortamından alamıyorsa; gönderme ve ayrıntılı değerlendirme basamakları ile bireyselleştirilmiş eğitim programının (BEP) hazırlanması ve programın değerlendirilmesi şeklinde devam eden basamakların yer aldığı bir süreçten geçer (Hanson vd., 2001; Küpper, 2000; Pierangelo ve Giuliani, 2007; Wood, 2002). Bu makalenin konusu olan 
gönderme öncesi süreç, akademik, duygusal ve davranışsal özellikleri yönünden genel eğitim müfredatını takip etmekte güçlük çeken öğrencilerin ayrıntılı değerlendirme için yönlendirilmeden önce çeşitli uyarlamalarla ve yapılanların kayıt altına alınarak genel eğitim sınıflarında eğitilmelerini amaçlayan bir süreçtir (Spinelli, 2012). Gönderme öncesi süreçte elde edilen verilerin kayıt altına alınmasının bazı yararları vardır. Öncelikle öğrencinin risk durumunun etiyolojisini, sorunu arttıran veya azaltan faktörlerin ortaya konmasına yardımcı olmaktadır. Aynı zamanda öğrenci için yapılan uyarlamaların öğrencinin başarı durumunun belirlenmesinde öğretmene kanıt sunmakta ve takibini sağlamaktadır. Bunun yanı sıra yapılan uyarlamaların sonuçlarını aileye veya okula belgelemek, ayrıntılı değerlendirmeye gönderme ile sonuçlanan girişimlerin nedenini nesnel bir şekilde ortaya konulmasına yardımcı olacaktır (Spinelli, 2012).

Risk grubu öğrenci eğitim-öğretim hayatına bulunduğu sınıf ortamında devam edebilir ya da özel eğitim hizmetlerine uygunluğunun tanımlanmasının ardından farklı bir eğitim ortamına gönderilebilir. Her iki seçenekte de verilecek olan kararların temelinde somut veriler yer almalıdır. Öğretmenden, gerek öğrencinin ayrıntılı değerlendirmeye gönderecek olan okul ve aile kararını, gerekse ayrıntılı değerlendirmeyi yapacak ve gönderme kararını verecek Rehberlik Araştırma Merkezi kararına yol gösterici olacak şekilde bir "Eğitsel Değerlendirme İsteği Formunu" doldurması beklenir (MEB, 2018a). Formu doldurmak için öğretmenin günlük ilerlemelerini kaydetmesi önemlidir. Gönderme öncesi süreçte veri toplama, ayrıntılı değerlendirme için ön değerlendirme işlevi de görebilir. Bu kritik bilgi elde etme süreci, öğrenci için karar verilirken risk durumunun kapsamlı bir şekilde anlaşılmasını sağlamaktadır (Spinelli, 2012).

Risk grubu öğrenciler için eğitim hayatlarının devamında, hangi eğitim ortamında bulunacakları, hangi destekleri alacakları ve bu desteği kimden alacakları konusunda belirleyici basamak gönderme öncesi süreç olmaktadır. Gönderme öncesi süreç okulda sınıf öğretmeni ve rehber öğretmen tarafından yönetilir. Öğretmen, öğrencinin gönderme ve ayrıntılı değerlendirmeye yönlendirilme kararını verebilmesi için yaptığı sınıf içi izleme ve değerlendirme verilerini öğretim sürecine ve ortamına aktaracak şekilde yönetmelidir. Öğrenci için yapılan uyarlamaların uygunluğu ve bu uyarlamalardan yararlanma durumunun sistematik olarak toplanan veriler ışığında ortaya konması, öğrenci hakkında varılan yargının doğruluğunun tespiti için önemlidir. Sınıf içinde ya da öğrencinin gelişimine etki eden diğer kişiler ve ortamlardan elde edilen öğrenci için de gerekli olan ve bir araya geldiğinde anlamlı bilgi elde edilebilecek veriler doğrultusunda karar verme sürecini yönetmek, öğretmenin öğrencisini doğru eğitim sürecine yönlendirmesini sağlayacaktır.

\section{Veriye Dayalı Karar Verme:}

Günümüzde veri, toplum dinamiğini oluşturan tüm alanlarda kararlar alınmasında önemli bir rol oynamaktadır. Müşteri davranışlarının analizine dayalı satış stratejileri oluşturan ticari 
kuruluşlarda, tedavi süreçlerini ve sonuçlarını değerlendirerek karar veren hastanelerde ve öğrenci ihtiyaçlarına yönelik uygulama süreci izleyen eğitim kurumlarında toplanan verilerle alınan kararlara yol göstermesi sağlanmaktadır (Lai ve Schildkamp, 2013). Eğitimde öğrenci başarısının hangi yönde olduğunun sistematik takibinin sağlanması açısından veriye dayalı kararların verilmesinin önemli olduğu vurgusu yapılmaktadır (Van Geel, Keuning, Visscher ve Fox, 2016). Bu bağlamda çoğu ülkedeki okullarda, veri toplama ve bunları kullanmaya yani veriye dayalı karar vermeye daha fazla önem verilmektedir (Datnow, Park ve Kennedy-Lewis, 2013; Mandinach ve Gummer, 2013b; Schildkamp, Karbautzki ve Vanhoof, 2014). Öğretmenlerden, kararlarının sadece deneyim ve sezgiye değil, aynı zamanda yüksek kaliteli verilere dayalı vermeleri beklenmektedir. Çeşitli araştırmalar, veriler kullanılarak verilen kararların hem öğrenci başarısı açısından hemde okulların başarısında olumlu etkilere yol açabileceğini göstermektedir (Campbell ve Levin, 2009; Carlson, Borman ve Robinson, 2011; Lai, McNaughton, Timperley ve Hsiao, 2009; McNaughton, Lai ve Hsiao, 2012).

Veriye dayalı karar verme (VDKV), birçok şekilde var olan veri biçiminin sistematik olarak toplanması ve alınan kararlara yol göstermesi için kullanılması anlamına gelmektedir (Choppin, 2002; Ikemoto ve Marsh, 2007; Marsh, Pane ve Hamilton, 2006). VDKV, hesap verilebilir bir sistem oluşumuna artı olarak, öğrenci merkezli, sınıf içinde farklılaştırılmış öğretimi destekleyen bir süreç olarak karşımıza çıkmaktadır. Verilerden elde edilen bilgiler öğretmenlere, öğrenme ve öğretme süreçlerine rehberlik etmek için kullanılabilir (Halverson, 2010). Bunun yanı sıra öğretmenlerin verdikleri eğitimi sınıfa ya da bireysel öğrenme ihtiyaçlarına göre uyarlamasına yardımcı olan kararları almalarına da imkân sunmaktadır (Rallis ve MacMullen, 2000).

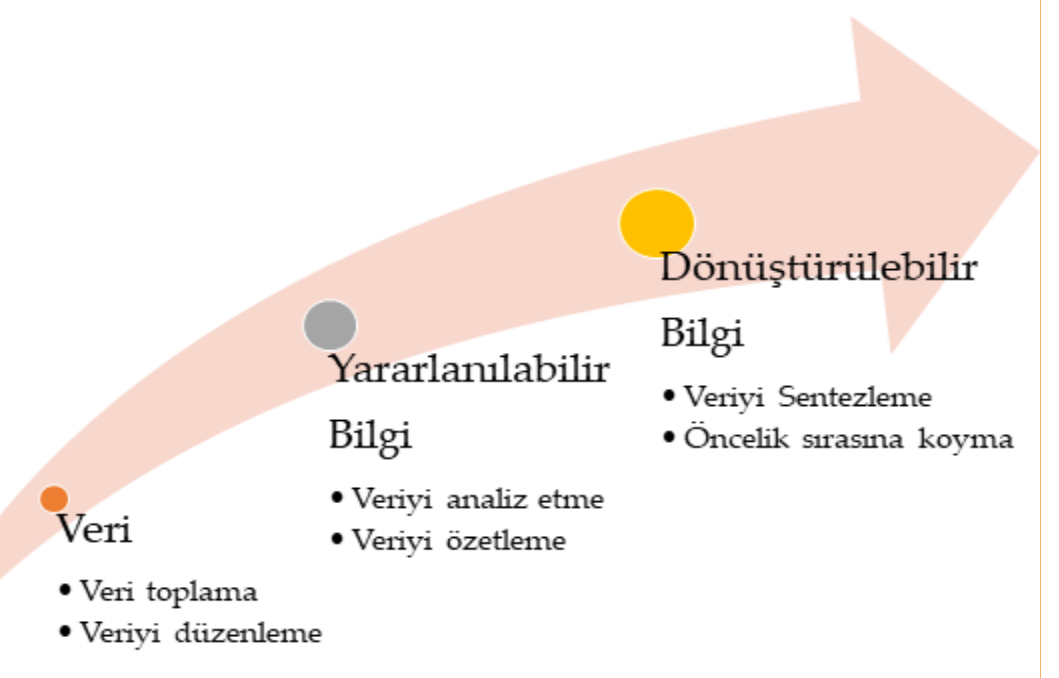

Şekil 1. Verinin Bilgiye Dönüşme Süreci

Veriye dayalı karar verme sürecini verinin bilgiye dönüşme süreci (Şekil 1) olarak nitelendirebiliriz. veri (data), ham olarak her durumda bulunmaktadır. Öğretmenler bu aşamada 
veriyi toplar ve organize ederler. Verileri yazılı sınavlar, portfolyo değerlendirmeleri, kontrol listeleri, sınıf içi çalışmaların sonuçları oluşturabilir. Bu veriler öğrencileri demografik bilgileri, sağlık bilgileri, davranışlarına ilişkin gözlemler sonucu toplanan verilerle de desteklenmektedir. Veriler kendi başlarına anlamsız olmakla birlikte, bilgiye dönüşüp dönüşmeyecekleri verilere bakan kişilerin bakış açısına ve anlayışına bağlı olmaktadır (Light, Wexler ve Heinze, 2004; Mandinach, 2012).

Yararlanılabilir bilgi (information), bir bağlama bağlandığında anlam verilen verilerdir. Veriler ve bağlam arasındaki ilişkilerin anlaşılmasına yardımcı olur. Ancak yararlanılabilir bilgi, verileri eyleme dönüştürmek için yetersiz kalmaktadır (Light vd., 2004). Bu düzeyde öğretmenler verileri analiz eder ve özetler. Yararlanılabilir bilgi öğrencilerin başarı durumlarını, performans örüntülerini ortaya koyarak öğretmenlere yoğunlaşan ve seyrekleşen verileri bakma fırsatı vermektedir. Öğretmenler öğrenci ya da öğrenci grubunun performans eğilimine ilişkin sistematik sonuçları karşılaştırarak elde ettiği özetlemeler ile müdahale ihtiyacı olan öğrencileri ortaya koyar. Analiz ve özetleme öğretmene müfredata ya da eğitim planına yönelik amaçları kazanan ya da kazanamayan öğrencilerin verilerini sayısal olmaktan bir adım öteye taşımaktadır (Mandinach, 2012).

Eyleme dönüştürülebilir bilgi (knowledge), öğretmenin öğrencilerin farklı bilgi, kavram ve becerilere yönelik ele edilen analiz puanları arasındaki bağlantıları görme ve sonra bunlara göre hareket ettiği düzeyi temsil eder (Light vd., 2004). Bu düzeyde bilgi sentezlenir, öncelik sırasına konulur. Öğrenci için planlanan müdahalenin ortaya konulması ve elde edilen bilginin uygulanabilir adımlara dönüşmesi kararına imkân sağlamaktadır (Mandinach, 2012).

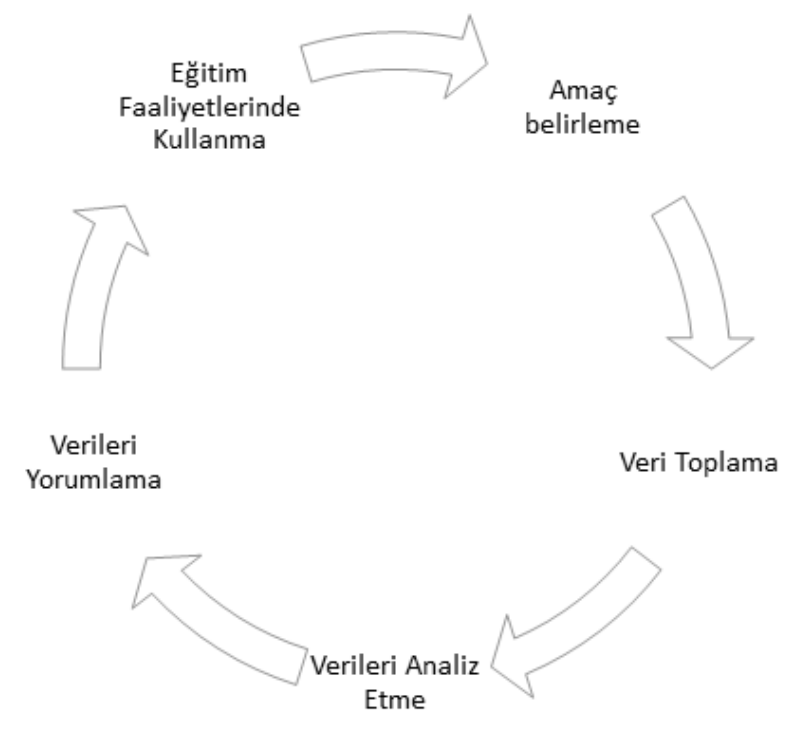

Şekil 2. Veri Okuryazarlığının Beş Ana Bileşeni

VDKV, sayılar veya verilerden daha fazlası olarak karşımıza çıkmaktadır. VDKV'nin amacı verileri yararlanılabilir ve dahası eğitim ortamında alınan kararlara yön veren eyleme 
dönüştürülebilir hale getirmektir (Kippers, Poortman, Schildkamp ve Visscher, 2018; Mandinach, 2012). Verileri eğitimde kullanımına yönelik eyleme dönüştürme becerisine veri okuryazarlığı (Mandinach, 2012) veya eğitimsel karar verme (Means, Chen, DeBarger ve Padilla, 2011) denir. Veri okuryazarlığı Şekil 2'de belirtildiği gibi; amaç belirlemeyi, veri toplamayı, verileri analiz etmeyi, verileri yorumlamayı ve eğitim öğretim ortamlarında kullanmayı içermektedir (Hamilton vd., 2009; Lai ve Schildkamp, 2013; Mandinach ve Gummer, 2016; Van Geel vd., 2016). Eğitimciler, VDKV'yi uygulamak için bu beş veri okuryazarlığı bileşenini kullanmaktadır (Kippers vd., 2018). Veri okuryazarlığ becerileri beş bileşenle birlikte, sorunların tanımlanmasını, verilerin yorumlanmasını, öğretimsel uyarlamaların planlanmasını, uygulanmasını ve izlenmesini de içermektedir (Mandinach ve Gummer, 2013a).

Amaç belirleme, öğretmenlerin verileri kullanma nedenlerini ortaya koydukları, öncelikle somut ve ölçülebilir şekilde problem tanımladıkları bileşendir (Coburn ve Turner, 2011; Ebbeler, Poortman, Shildkamp ve Pieters, 2017; Kippers, vd., 2018; Mandinach ve Grummer, 2016). Veri toplama, veri okur-yazarı olmak için önemli bir beceridir. Veriler görüşme şeklinde nitel olarak toplanabileceği gibi, sınav sonuçları şeklinde nicel olarak da toplanabilir. Üçüncü bileşen olan verileri analiz etme, elde edilen verinin organize edilmesi ve önceliğine karar verilmesi, çeşitli istatistiksel yöntemleri kullanarak (örn., ortalama ve standart sapmayı hesaplama gibi) verilerin analizinin yapılması becerilerini içermektedir (Coburn ve Turner, 2011; Ebbeler vd., 2017; Mandinach ve Grummer, 2016; Kippers vd., 2018). Veri analizinde, verilerin bir Excel tablosu yardımiyla grafikleştirilerek öğrenci performansının özetlenmesi ve değerlendirilmesi sağlanabilir. Veri okuryazarlı̆̆ı kavramının bir diğer bileşeni de verileri yorumlamadır. Öğretmenlerin analiz edip özetlediği verilerin kendilerini başlangıçtaki amaçlarına yönelik bir sonuca götürme durumlarını belirleme becerilerini içermektedir (Coburn ve Turner, 2011; Ebbeler vd., 2017; Kippers vd., 2018; Mandinach ve Grummer, 2016; Marsh, 2012). Eğitim faaliyetlerinde bulunma bileşeni öğretmenlerin verilere yönelik yorumlarını, eğitim ortamında kullanma becerisini içermektedir (Coburn ve Turner, 2011; Ebbeler vd., 2017; Kippers vd., 2018; Mandinach ve Grummer, 2016). Veri okuryazarlığ1 bileşenleri öğretmenleri veriye dayalı karar vermeye götüren yolda sistematik ilerlemelerine yardım edecek olan becerileri içermektedir. VDKV, öğrencilerin şu anki öğrenmeleri ve olması beklenen öğrenme durumları arasındaki farkı ortaya koyarak, öğretmene destek bir yapı sunmaktadır. Bununla birlikte öğrenci hakkında verilen kararların uygunluğu, öğretmenlerin gerekli veri okuryazarlığı becerilerine sahip olmalarını gerektirmektedir (Lai, Wilson, McNaughton ve Hsiao, 2014; Van Geel vd., 2016).

Verinin bilgiye dönüştürüldüğü VDKV, sistematik ve yinelenen bir süreç olarak karşımıza çıkmaktadır. Ek olarak belirli esneklikleri de bize sunmaktadır. Veri toplama işinin her bir basamakta 
devam edebilme veya ihtiyaç halinde ek verilerin de toplanabileceği düşüncesi bilgiye daha geniş bir pencereden ulaşmayı sağlamaktadır (Mandinach, 2012). VDKV, öğretmenlerin öğretim süreçlerini öğrencilerinin performansları doğrultusunda düzenlemelerine yardımcı olacak olan kayıtlı ve süreç içinde geliştirilebilir şekilde bilgiyi elde etmelerine yardımcı olmaktadır (Dunn, Airola, Lo ve Garrison, 2013). Öğrenci ile ilgili toplanan veri, öğrencinin bulunduğu eğitim ortamından en yüksek yararı elde etmesi için verilen kararlarda kullanılmaktadır. Veriler öğretmenlerin sürekli farklılaşan eğitim ortamında, işleyişin müfredat amaçlarının ne ölçüde karşıladığını izlemelerine, sorunlar oluştuğunda çözülmesi gereken zamanda somut sonuçlara dayalı bir şekilde karar vermelerine yardımcı olmaktadır (Schildkamp ve Kuiper, 2010). Öğretmenlerin kararlarını devam eden bir süreçte sürekli değerlendiriyor olmalarının, öğrenci başarısını da olumlu yönde etkilediği ortaya konulmuştur (Lai vd., 2014; McNaughton vd., 2012; Poortman ve Schildkamp, 2016; Terrill, 2018; Van Geel vd., 2016).

\section{Gönderme Öncesi Süreçte VDKV'nin Önemi}

Gönderme öncesi süreç, öğrencilerin bulundukları eğitim ortamlarında sürece devam etmesini sağlarken, sürecin öğrencinin akademik, davranışsal veya sosyal performansını iyileştirmek için öğretmenlerin sistematik girişimlerde bulunmasına izin vermektedir. Gönderme öncesi süreç, öğrenciyi doğrudan tanılamaktan ziyade tanımaya yönelik yapılan çalı̧̧malara yön verecek sonuçları elde etme ile başlayacaktır. Bu noktada öğretmene yardımı olacak ilk araç değerlendirme sonuçlarıdır. Bu süreçte öğretmenlerin öğrencilerinin gelişimine yönelik kanıtlar elde etmek için veriye dayalı karar vermesi gerektiği belirtilmektedir (Militello, Fusarelli, Alsbury ve Warren, 2013).

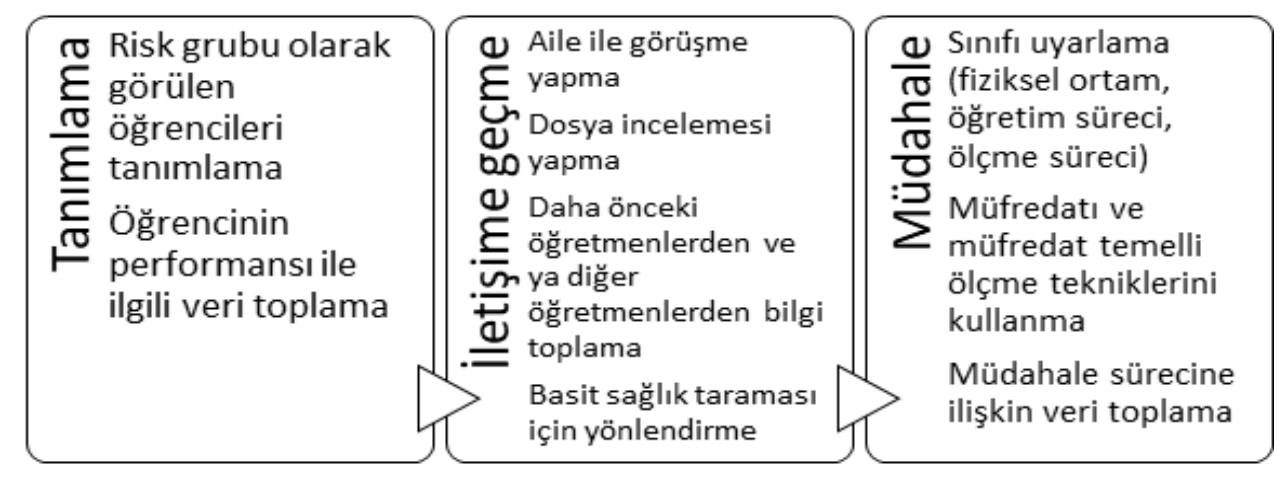

Şekil 3. Gönderme Öncesi Sürecin Bileşenleri ve Sırası

Paet-Bullaoit, S. (2019). Policy documents and the pre-referral process in BC schools (Master's Thesis). http://dx.doi.org/10.25316/IR-5510 kaynağından uyarlanmıştır.

Şekil 3'te gönderme öncesi sürecin her aşamasında veri toplandığ1 ve toplanan veriler doğrultusunda sürecin yönlendirildiği görülmektedir (Paet-Bullaoit, 2019). Öğrenciyi tanımaya yönelik bilgilerden başlanılarak, uygulamaların planlanması için kullanılacak bilgilere kadar öğretmenin veri topluyor olması gerekmektedir. Öğretmenin müdahaleyi planlaması açısından risk 
durumlarını tanımlaması ve öğrenciyi tanıması açısından gerekli yerler ve kişilerle iletişime geçerek sınıf içi gözlem ve değerlendirme verilerine destek olabilecek veriler elde etmesi sürecin devamına yol gösterici niteliktedir. VDKV gönderme öncesi süreçte her bir bileşenin kendi içinde verilerinin toplanarak sürecin uygunluğunun yani verilen kararların değerlendirilmesine imkân tanımaktadır.

Öğrencilerin bulundukları eğitim ortamlarından en üst düzeyde yararlanmaları önemlidir. Bu da ancak öğretmenlerin izleme ve değerlendirmeleri sonuçlarına dayanarak karar almaları ve öğrencilerin eğitim ortamlarını bu kararlar doğrultusunda düzenlemelerine bağlıdır. Gönderme öncesi süreç, risk grubu öğrenci için bulunduğu eğitim ortamında öğretim süreçlerini kendi ihtiyaçlarına yönelik uyarlanması ve bu uyarlamalardan yararlanma durumunun toplanan veriler ışı̆̆ında verilen kararlar ile ortaya konmasıdır. Öğretmenlerin gönderme öncesi süreçte iki farklı rolü benimsedikleri görülmektedir. İlkinde öğretmen, sistematik yapılan sınıf içi değerlendirme sonuçlarına dayalı olarak öğretimsel kararların almakta ve risk grubu öğrencilerin eğitsel tanı almadan bulundukları eğitim ortamlarında dâhil olmalarını sağlamaktadır (Fuchs, Fuchs, Bahr, Fernstrom ve Stecker, 1990; Good, 2004; Kargın, 2007; Noll, Kamps ve Seaborn, 1993; Soukup, Wehmeyer, Bashinski ve Bovaird, 2007). Diğer bir yol olarak öğretmenler risk grubu olarak düşündükleri öğrencileri için özel eğitime yönlendirici rolü üstlenmektedir. Öğretmenlerin bu davranışı öğrencilerinin eğitim ortamlarından ihtiyaçlarına yönelik olarak faydalanması engellenmesine neden olmaktadır. Akademik, davranışsal veya sosyal-duygusal sorunlar yaşayan bir öğrenciyi daha kapsamlı bir değerlendirme için yönlendirmeden önce, öğretmenlerden gönderme öncesi süreçte özellikle de sorunu iyileştirmeye çalışan stratejileri ve düzenlemeleri uygulamaları ardından da belgelendirmeleri beklenir. Gönderme öncesi sürecin belgelenmesi öğrencinin sorununun etiyolojisini belirlemek ve sorunu ortaya çıaran veya sorunu azaltan faktörlerin ortaya konulmasına yardımcı olmak için yararlı bilgiler sağlamaktadır. Öğretmenin elinde olan sürece ilişkin kayıtlar sınıfta sorunla başa çıkmak için yapılan girişimler hakkında ebeveynleri bilgilendirmeye yönelik ve öğrenciyi yönlendirmeyle sonuçlanacak olan endişenin nedenini daha da açıklığa kavuşturmaya ilişkin kanıtlar sunmaktadır. Gönderme öncesi sürece ilişkin kayıtlar öğretmenin uyguladığı müdahalelerin hangisinin başarılı olup olmadığı ve ne ölçüde başarılı olduğunun ortaya konulmasını sağlamaktadır (Spinelli, 2012). Öğrencinin öğrenim hayatının devamında öğrenme özelliklerine ilişkin dikkate alınması gereken bilgiler gönderme öncesi süreçte veriye dayalı alınan kararlar ile mümkün olmaktadır. Gönderme öncesinde uygulanan bu kritik bilgi toplama süreci sırasında elde edilen bilgiler, çocuğun kapsamlı bir şekilde anlaşılmasını sağlamaktadır.

\section{Sonuç}

VDKV gönderme öncesi süreçte öğrencinin özellikle de desteğe ihtiyaç duyduğu düşünülen öğrencinin destek türüne karar verme yolunda yol haritasının çizilmesini sağlamaktadır. Bu yaklaşım, 
öğretmenin aldığı kararlara doğrudan veriye dayalı güçlü kanıtlar sunmaktadır. Deneyimleri benzer durumlarla karşılaştıklarında öğretmenleri benzer kararlar almaya yönlendirirken VDKV öğretmenlerin kendi yeterliklerine sınırlı kalmadan, çocuk için yapılanları bireyselleştirerek karşılaştırmalı olarak sorgulanabilir ve elden geçirilebilir hale getirmesini sağlar. Öğretmen durumların ortaya çıktığı anları da içerecek şekilde veri toplarken, öğrencilerin ihtiyacı olan desteği de fark edip gerekli düzenlemeleri yapabilir. Öğretmenin VDKV mantığıyla yaptığı düzenlemeler üzerinden verdiği kararları tekrarlı biçimde sorgulama, edindiği bilgi bütünü içerisinden öğrencisi için olası en iyiyi bulma fırsat yaratacaktır.

VDKV'de işleyişi itibariyle dinamik ve süreklilik içeren bir akışı getirir ve bu durum öğretmeni öğrenciyi etiketleme ile biten, sorun temelli düşünme yerine, öğrenci özelinde çözüm arayışının göstergesi olan öğrenci için uygun olanı bulma yaklaşımına yakınlaştıracaktır. Öğretmen süreçte öğrencisinin bilgi ve beceriye ulaşmasına yardımcı olacak erişim ve katılım kanallarını açacak yeni yollar deneyebilecektir. Bu yollar öğrencinin öğrenci performansını olumlu ve olumsuz etkileyen tercih ve uygulamaların da kayıt altına alınabilmesini de sağlayacaktır. Öğretmenin eli işe yaramayan uygulamaları nasıl geliştireceği ile ilgili toplamaya devam ettiği verilerle daha güçlü olmaktadır.

VDKV'nin öğrenci yönüne bakıldığında özellikle akranları ile eğitim görmeye devam edecek olan risk grubu öğrencinin gelişimine olumlu yansıyacaktır. Akranları ile fiziki birliktelikten ziyade akranları ile birlikte sürecin içinde bir birey olması destekleyici gerekli düzenlemelerle birlikte yürümeye devam edecektir. Akranların ve öğretmenin önyargılarından ve olumsuz sınıf ortamından sıyrılmış bir ortamda eğitimine devam etme fırsatı olacaktır.

Özetle, risk grubu olarak tanımlanan öğrenciler için uygun kararlar, onların eğitsel gelişmelerini yakından takip eden öğretmenlerin ellerindeki verilere dayalı aldıkları kararlarına bağlıdır. Öğretmenler veriyi nasıl toplayacağı bilgisine sahiptir. Topladıkları veriler ile başa çıkma ya da bu verileri eğitsel faaliyetlere yansıtma becerileri veri okuryazarlığından geçmektedir. Öğretmenlerin veri okuryazarlığı ile oluşturdukları bilgi yumağı risk grubu öğrencinin eğitim sürecini nitelikli devam ettirmesine yani öğretmenin süreci şekillendirmesine yardımcı olacaktır. Öğretmenlerin risk grubu öğrenciler ile ne yapacaklarını düşünmeye başladıkları andan itibaren sınıfta var olan veriyi bir sistematik çerçevesinde kararlarına yansıtmaları gerektiğinin farkında olmalarının önemli olduğu düşünülmektedir.

\section{Kaynaklar}

Anderson, L. W. (2003). Classroom assessment: Enhancing the quality of teacher decision making. New Jersey: Routledge.

Black, H. D. (1983). Introducing diagnostic assessment. Programmed Learning and Educational Technology, 20(1), 58-63. 
Black, P., Wilson, M., \& Yao, S. Y. (2011). Road maps for learning: A guide to the navigation of learning progressions. Measurement: Interdisciplinary Research \& Perspective, 9(2-3), 71-123.

Campbell, C., \& Levin, B. (2009). Using data to support educational improvement. Educational Assessment, Evaluation and Accountability (formerly: Journal of Personnel Evaluation in Education), 21(1), 47.

Carlson, D., Borman, G. D., \& Robinson, M. (2011). A multistate district-level cluster randomized trial of the impact of data-driven reform on reading and mathematics achievement. Educational Evaluation and Policy Analysis, 33(3), 378-398.

Chen, P. P., \& Bonner, S. M. (2020). A framework for classroom assessment, learning, and selfregulation. Assessment in Education: Principles, Policy \& Practice, 27(4), 373-393. doi: $\underline{10.1080 / 0969594 X .2019 .1619515}$

Choppin, J. (2002, April). Data use in practice: Examples from the school level. Annual meeting of the American Educational Research Association'da sunulmuş bildiri. New Orleans, LA.

Coburn, C. E., \& Turner, E. O. (2011). Research on data use: A framework and analysis. Measurement: Interdisciplinary Research \& Perspective, 9(4), 173-206.

Çuhadar, S. (2017). Sınıf öğretmenlerinin eğitsel değerlendirme sürecine ilişkin görüşleri. Trakya Üniversitesi Ĕ̆itim Fakültesi Dergisi, 7(2), 526-549.

Datnow, A., Park, V., \& Kennedy-Lewis, B. (2013). Affordances and constraints in the context of teacher collaboration for the purpose of data use. Journal of Educational Administration, 51(3), 341-362.

Dunn, K. E., Airola, D. T., Lo, W. J., \& Garrison, M. (2013). Becoming data driven: The influence of teachers' sense of efficacy on concerns related to data-driven decision making. The Journal of Experimental Education, 81(2), 222-241. doi: 10.1080/00220973.2012.699899

Ebbeler, J., Poortman, C. L., Schildkamp, K., \& Pieters, J. M. (2017). The effects of a data use intervention on educators' satisfaction and data literacy. Educational Assessment, Evaluation and Accountability, 29(1), 83-105.

Flaherty, L. T., \& Osher, D. (2003). History of school-based mental health services in the United States. M. D. Weist, S. W. Evans, \& N. A. Lever (Ed.), Handbook of school mental health advancing practice and research içinde (s. 11-22). Boston, MA: Springer.

Frey, J. R. (2019). Assessment for special education: Diagnosis and placement. The ANNALS of the American Academy of Political and Social Science, 683(1), 149-161.

Fuchs, D., Fuchs, L. S., Bahr, M. W., Fernstrom, P., \& Stecker, P. M. (1990). Prereferral intervention: A prescriptive approach. Exceptional Children, 56(6), 493-513. 
Good, K. I. (2004). The experiences of parents with the pre-referral process: An evolutionary perspective (Doctoral dissertation). ProQuest Dissertations and Theses database. (UMI No. 3124507).

Gresham, F. M. (1997). Social competence and students with behavior disorders: Where we've been, where we are, and where we should go. Education and Treatment of Children, 20(3), 233-249.

Halverson, R. (2010). School formative feedback systems. Peabody Journal of Education, 85(2), 130-146. doi: $\underline{10.1080 / 01619561003685270}$

Hamilton, L., Halverson, R., Jackson, S. S., Mandinach, E., Supovitz, J. A., \& Wayman, J. C. (2009). Using Student Achievement Data to Support Instructional Decision Making. IES Practice Guide. NCEE 2009-4067. National Center for Education Evaluation and Regional Assistance.

Hanson, M. J., Horn, E., Sandall, S., Beckman, P., Morgan, M., Marquart, J., ..., \& Chou, H. Y. (2001). After preschool inclusion: Children's educational pathways over the early school years. Exceptional Children, 68(1), 65-83.

Ikemoto, G. S., \& Marsh, J. A. (2007). Chapter 5 cutting through the "data-driven" mantra: Different conceptions of data-driven decision making. Yearbook of the National Society for the Study of Education, 106(1), 105-131.

Kane, M. T., \& Wools, S. (2020). Perspectives on the validity of classroom assessments. S. M. Brookhart, \& J. H. McMillan (Ed.), Classroom assessment and educational measurement içinde (s. 11-26). New York: Routledge.

Kargın, T. (2007). Eğitsel değerlendirme ve bireyselleştirilmiş eğitim programı hazırlama süreci. Ankara Üniversitesi Ĕ̆itim Bilimleri Fakültesi Özel Eğitim Dergisi, 8(01), 1-15.

Kippers, W. B., Poortman, C. L., Schildkamp, K., \& Visscher, A. J. (2018). Data literacy: What do educators learn and struggle with during a data use intervention? Studies in Educational Evaluation, 56(2018), 21-31.

Küpper, L. (2000). A Guide to the Individualized Education Program. Office of Special Education an Rehabilitative Services, Washington, DC.

Lai, M. K., McNaughton, S., Timperley, H., \& Hsiao, S. (2009). Sustaining continued acceleration in reading comprehension achievement following an intervention. Educational Assessment, Evaluation and Accountability (formerly: Journal of Personnel Evaluation in Education), 21(1), 81100.

Lai, M., \& Schildkamp, K. (2013). Data-based decision making: An overview. Schildkamp, K., Lai M., \& Earl, L. (Ed.) Data-based decision making in education: Studies in educational leadership. Dordrecht: Springer. https://doi.org/10.1007/978-94-007-4816-3 2 
Lai, M. K., Wilson, A., McNaughton, S., \& Hsiao, S. (2014). Improving achievement in secondary schools: Impact of a literacy project on reading comprehension and secondary school qualifications. Reading Research Quarterly, 49(3), 305-334. doi: 10.1002/rrq.2014.49.issue-3

Light, D., Wexler, D., \& Heinze, J. (2004). How practitioners interpret and link data to instruction: Research findings on New York City Schools' implementation of the Grow Network. Annual Meeting of the American Educational Research Association'da sunulmuş bildiri, San Diego, CA.

Mandinach, E. B. (2012). A perfect time for data use: Using data-driven decision making to inform practice. Educational Psychologist, 47(2), 71-85.

Mandinach, E. B., \& Gummer, E. S. (2013a). Defining data literacy: A report on a convening of experts. Journal of Educational Research and Policy Studies, 13(2), 6-28.

Mandinach, E. B., \& Gummer, E. S. (2013b). A systemic view of implementing data literacy in educator preparation. Educational Researcher, 42(1), 30-37.

Mandinach, E. B., \& Gummer, E. S. (2016). What does it mean for teachers to be data literate: Laying out the skills, knowledge, and dispositions. Teaching and Teacher Education, 60, 366-376.

Marsh, J. (2012). Interventions promoting educators' use of data: Research insights and gaps. Teachers College Record, 114(11), 1-48.

Marsh, J. A., Pane, J. F., \& Hamilton, L. S. (2006). Making Sense of Data-Driven Decision Making in Education: Evidence from Recent RAND Research. Occasional Paper. Rand Corporation.

McAlenney, A. L., \& Coyne, M. D. (2011). Identifying at-risk students for early reading intervention: Challenges and possible solutions. Reading \& Writing Quarterly, 27(4), 306-323.

McMillan, J. H. (2017). Classroom assessment: Principles and practice that enhance student learning and motivation. New York: Pearson.

McNaughton, S., Lai, M., \& Hsaio, S. (2012). Testing the effectiveness of an intervention model based on data use: A replication series across clusters of schools. School Effectiveness and School Improvement, 23(2), 203-228. doi: $\underline{\text { 10.1080/09243453.2011.652126 }}$

Means, B., Chen, E., DeBarger, A., \& Padilla, C. (2011). Teachers' Ability to Use Data to Inform Instruction: Challenges and Supports. Office of Planning, Evaluation and Policy Development, US Department of Education.

MEB. (2018a). Rehberlik ve Araştırma Merkezi Kılavuzu. https://orgm.meb.gov.tr/meb iys dosyalar/ 2018 01/17234231 ram kilavuzu 2018.pdf sayfasından erişilmiştir.

MEB. (2018b). Özel Eğitim Hizmetleri Yönetmeliği. http://orgm. meb.gov.tr/ sayfasından erişilmiştir. 
Militello, M., Fusarelli, B., Alsbury, T., \& Warren, T. P. (2013). How professional standards guide practice for school principals. International Journal of Educational Management, 27(1), 7490. https://doi.org/10.1108/09513541311289837

Noll, M. B., Kamps, D., \& Seaborn, C. F. (1993). Prereferral intervention for students with emotional or behavioral risks: Use of a behavioral consultation model. Journal of Emotional and Behavioral Disorders, 1(4), 203-214.

Overton, T. (2012). Assessing learners with special needs an applied approach. (7th Ed.). New Jersey: Pearson Education.

Özmen, E. R. (2012). Zihin engellilerde öğretmenlik uygulaması öğrencilikten öğretmenliğge geçiş süreci. Ankara: Pegem Akademi.

Özyürek, M. (2015). Özel eğitimde ölçümleme ve değerlendirme. Ankara: Kök Yayıncıllk.

Paet-Bullaoit, S. (2019). Policy documents and the pre-referral process in BC schools (Master's Thesis). http://dx.doi.org/10.25316/IR-5510

Pierangelo, R., \& Giuliani, G. (Ed.). (2007). Understanding assessment in the special education process: A step-by-step guide for educators. California: Corwin Press.

Poortman, C. L., \& Schildkamp, K. (2016). Solving student achievement focused problems with a data use intervention for teachers. Teaching and Teacher Education, 60, 425-433. doi: 10.1016/j.tate.2016.06.010

Rallis, S. F., \& MacMullen, M. M. (2000). Inquiry-minded schools: Opening doors for accountability. Phi Delta Kappan, 81(10), 766-773.

Reschly, D. J. (1996). Identification and assessment of students with disabilities. The Future of Children, $6(1), 40-53$.

Russell, M. K., \& Airasian, P. W. (2012). Classroom assessment: Concepts and applications. New York: McGraw-Hill Companies.

Saefurrohman, S., \& Balinas, E. S. (2016). English teachers classroom assessment practices. International Journal of Evaluation and Research in Education, 5(1), 82-92.

Sagor, R., \& Cox, J. (2013). At risk students: Reaching and teaching them. New York: Routledge.

Salvia, J., Ysseldyke, J., \& Bolt, S. (2010). Assessment: In special and inclusive education, (11th Ed.). Belmont: Wadsworth, Cengage Learning.

Schildkamp, K., Karbautzki, L., \& Vanhoof, J. (2014). Exploring data use practices around Europe: Identifying enablers and barriers. Studies in Educational Evaluation, 42, 15-24.

Schildkamp, K., \& Kuiper, W. (2010). Data-informed curriculum reform: Which data, what purposes, and promoting and hindering factors. Teaching and Teacher Education, 26(3), 482-496. 
Shermis, M. D., \& DiVesta, F. J. (2011). Classroom assessment in action. Maryland: Rowman \& Littlefield.

Slavin, R. E., \& Madden, N. A. (1989). What works for students at risk: A research synthesis. Educational Leadership, 46(5), 4-13.

Soukup, J. H., Wehmeyer, M. L., Bashinski, S. M., \& Bovaird, J. A. (2007). Classroom variables and access to the general curriculum for students with disabilities. Exceptional Children, 74(1), 101120.

Spinelli, C. G. (2012). Classroom assessment for students in special and general education. New Jersey: Pearson Education.

Strickland, B. B., \& Turnbull, A. P. (1990). Developing and implementing individualized education programs. Columbus, OH: Merrill.

Terrill, T. A. (2018). Data-driven instruction from the perspective of administrators and teachers. (Doctoral Thesis). http://cardinalscholar.bsu.edu/handle/123456789/201495 sayfasından erişilmiştir.

Tomlinson, C. A., \& Moon, T. R. (2013). Assessment and student success in a differentiated classroom. Virginia: ASCD.

Tunç, Z. (2011). Sinıf öğretmenlerinin risk taşıyan öğrenciler için gönderme öncesi sürece ilişkin görüşleri. (Yüksek lisans tezi). https://tez.yok.gov.tr sayfasından erişilmiştir.

Van Geel, M., Keuning, T., Visscher, A. J., \& Fox, J. P. (2016). Assessing the effects of a school-wide data-based decision-making intervention on student achievement growth in primary schools. American Educational Research Journal, 53(2), 360-394.

Vaughn, S., Bos, C. S., \& Schumm, J. S. (2018). Teaching students who are exceptional, diverse, and at risk in the general education classroom. New York: Pearson.

Weist, M. D. (1997) Expanded school mental health services. T. H. Ollendick, \& R. J. Prinz (Ed.) Advances in clinical child psychology. Boston, MA: Springer. https://doi.org/10.1007/978-1-47579035-19

Wood, J. W. (2002). Adapting instruction to accommodate students in inclusive settings (3rd Ed.). Columbus. OH: Merrill/Prentice Hall.

\section{Extended Summary}

In-class monitoring and evaluation is defined as the process of obtaining information in order to compare students' progress with specified curriculum goals (Shermis \& DiVesta, 2011). This process of acquiring knowledge becomes the main decision-making resource for teachers to organize and plan in the classroom by turning information into meaning. The purposes of classroom monitoring and evaluation include identifying individual differences among students, planning and conducting 
teaching, providing students with feedback and motivation, identifying students' risk situations and need for supportive education, and assessing progress (Frey, 2019; Russell \& Airasian, 2012).

The teacher must make certain decisions to plan and shape the teaching process. If the teacher wants to determine success, he/she should collect data as close to the decision as possible. If he/she wants to obtain information about learning, he/she should make a plan for collecting data in the process (Anderson, 2003). Data collection times within the teaching process can be listed as before, during, and after teaching (McMillan, 2017; Özmen, 2012; Shermis \& DiVesta, 2011; Tomlinson \& Moon, 2013). Determining the different learning characteristics of students will guide the teacher to focus on the points that need to be differentiated in classroom teaching, monitoring and evaluation. The teacher will organize the teaching process and assessment tools in a way that will enrich and appeal to all students.

A wide variety of students or student groups are encountered in a classroom in terms of individual learning characteristics. In this class with students with various characteristics, teachers may need to make a definition for their students who do not belong to a certain group. In this context, the risk group students statement appears when we need to refer to a different student category (Sagor \& Cox, 2013). A student who has perceptual or environmental concerns in terms of social, academic, emotional, behavioral, language or health in the school environment is determined as the risk group student (Pierangelo \& Giuliani, 2007). Students who are unlikely to graduate from school on the basis of various risk factors are also defined as at-risk students. Among these risk factors, low achivement, failure in class, social-adaptive or behavioral problems, low attendance, low socioeconomic level or attendance to a school with low socio-economic level are considered (Flaherty \& Osher, 2003; Slavin \& Madden, 1989; Tunç, 2011; Weist, 1997). Teachers are the primary and reliable source for recognizing risk group students in the classroom (Gresham, 1997). The starting point of the attempts to determine the points that the teaching and learning environment should differ for students who are noticed to improve differently in the classroom is to collect data. In line with the data collected and further information, the risk group was determined based on the student data and the education process will continue in this direction. In this study, risk group students were handled within the framework of the teacher's in-class monitoring and evaluation studies in the process of recognition and pre-referral.

In our country, educational diagnosis is made to determine the need for special education according to Special Education Services Regulation (ÖEHY). According to the ÖEHY, the educational diagnosis process consists of educational evaluation and diagnosis, education plan preparation, orientation and monitoring stages (Ministry of National Education [MNE], 2018b). A student who is considered to be a risk group goes through a process stated as educational evaluation and diagnosis in 
the literature which begins with the process whose first two steps are first determination/screening and Pre-referral process (Hanson et al., 2001; Küpper, 2000; Pierangelo \& Giuliani, 2007; Wood, 2002). The pre-referral process, which is the subject of this article, is a process that aims to educate students who have difficulties in following the general education curriculum in terms of academic, emotional and behavioral characteristics, with various adaptations and by recording what has been done in general education classes before being directed for detailed assessment (Spinelli, 2012). For the students in the risk group, the determining step in the continuation of their education life, in which educational environment they will be in, what support they will receive and from whom they will receive this support is the pre-referral process.

DDDM means the systematic collection of existing data formats in many ways and using them to guide the decisions taken (Choppin, 2002; Ikemoto \& Marsh, 2007; Marsh, Pane, \& Hamilton, 2006). The information obtained from the data can be used to guide teachers in learning and teaching processes (Halverson, 2010). In addition, it allows teachers to make decisions that help them adapt their education to the classroom or to individual learning needs (Rallis \& MacMullen, 2000). Data is available in all cases in raw form. Useful information is data that is made meaningful when connected to a context. It helps to understand the relationships between data and context. However, usable information is insufficient to turn data into action. Actionable knowledge represents the level at which the teacher sees the connections between students' analysis scores for different knowledge, concepts and skills and then acts accordingly (Light et al., 2004).

DDDM is more than just numbers or data. The purpose of DDDM is to make the data usable and, moreover, transformable into action that guides the decisions made in the educational environment (Kippers, Poortman, Schildkamp, \& Visscher, 2018; Mandinach, 2012). The ability to transform data into action for its use in education is called data literacy (Mandinach, 2012) or educational decision making (Means, Chen, DeBarger, \& Padilla, 2011). Data literacy as indicated in Figure.2; includes goal setting, collecting data, analyzing data, interpreting data and using it in educational environments (Hamilton et al., 2009; Lai \& Schildkamp, 2013; Mandinach \& Gummer, 2016a; Van Geel, Keuning, Visscher, \& Fox, 2016).

The pre-submission process will start with obtaining the results that will guide the work done to get to know the student rather than directly diagnose it. At this point, the first tool that will help the teacher is the evaluation results. In this process, it is stated that teachers need to make data-based decisions in order to obtain evidence for the development of their students (Militello, Fusarelli, Alsbury, \& Warren, 2013). The pre-submission process is the adaptation of the teaching processes in the education environment according to the needs of the student at the risk group and the use of these adaptation decisions made in the light of the collected data. Documenting the pre-submission process 
provides useful information to determine the etiology of the student's problem and to help highlight the factors that raise or mitigate the problem. The records regarding the pre-submission process enable it to be revealed which interventions applied by the teacher were successful and to what extent they were successful (Spinelli, 2012).

DDDM provides a road map for the decision making regarding the student, especially the student considered as in need of support, in the pre-referral process. This approach provides the teacher with strong data-driven evidence on his/her decisions. Repeatedly questioning the decisions made through the arrangements done with the DDDM logic will allow the teacher to create an opportunity through his/her body of information for his/her student.

In summary, appropriate decisions for students defined as the risk group depend on the decisions made by teachers based on the data they have, who closely follow their educational progress. Teachers have the knowledge of how to collect data. Their ability to cope with the data they collect or to reflect these data on educational activities depends on data literacy. Web of information created by the teacher with data literacy will help the student at risk group to continue the education process in a qualified way, that is, it will allow the teacher to shape the process. When they start thinking about what to do with risk group students the teachers should be aware that the way they should look is to reflect the data available in the classroom in a systematic framework to their decisions.

\section{Araştırmacıların Katkı Oranı Beyanı}

$\mathrm{Bu}$ araştırmaya yazarlar eşit oranda katkı sağlamışlardır.

\section{Destek ve Teşekkür Beyanı}

$\mathrm{Bu}$ araştırmada herhangi bir kurum, kuruluş ya da kişiden destek alınmamıştır.

\section{Çatışma Beyanı}

Araştırmacıların araştırma ile ilgili diğer kişi ve kurumlarla herhangi bir kişisel ve finansal çıkar çatışması yoktur.

\section{Etik Kurul Beyanı}

$\mathrm{Bu}$ araştırma derleme türünde olduğundan etik kurul kararı gerektirmemektedir. 